Int. J. Electrochem. Sci., 16 (2021) Article ID: 210772

International Journal of

ELECTROCHEMICAL

SCIENCE

www.electrochemsci.org

\title{
Facile Hydrothermal Synthesis of Cubic Zinc Ferrite Nanoparticles for Electrochemical Detection of Anti- inflammatory Drug Nimesulide in Biological and Pharmaceutical Sample
}

\author{
Jeyaraman Anupriya ${ }^{1}$, Sivakumar Musuvadhi Babulal ${ }^{1}$, Tse-Wei Chen ${ }^{1,2}$, Shen-Ming Chen ${ }^{1, *}$, \\ Jeyaraj Vinoth Kumar ${ }^{3}$, Jeong-Won Lee ${ }^{3}$, Syang-Peng Rwei ${ }^{2,4}$, Jaysan $\mathrm{Yu}^{5}$, Richard $\mathrm{Yu}^{5}$, \\ Cheng-Yu Hong ${ }^{1}$ \\ ${ }^{1}$ Electroanalysis and Bioelectrochemistry Lab, Department of Chemical Engineering and \\ Biotechnology, National Taipei University of Technology, No. 1, Section 3, Chung-Hsiao East Road, \\ Taipei 106, Taiwan, ROC \\ ${ }^{2}$ Research and Development Center for Smart Textile Technology, National Taipei University of \\ Technology, Taipei 106, Taiwan, ROC. \\ ${ }^{3}$ Advanced Nano Surface Engineering Laboratory, Department of Mechanical Engineering, Chosun \\ University, 309, Pilmun-daero, Dong-gu, Gwangju 61452, Republic of Korea. \\ ${ }^{4}$ Institute of Organic and Polymeric Materials, National Taipei University of Technology, Taiwan \\ ${ }^{5}$ Well Fore special wire corporation, 10, Tzu-Chiang 7 rd., Chung-Li Industrial Park, Taoyuan, Taiwan \\ *E-mail: smchen78@ms15.hinet.net
}

doi: $10.20964 / 2021.07 .72$

Received: 2 April 2021 / Accepted: 21 May 2021 / Published: 31 May 2021

In this present work, a cubic $\mathrm{ZnFe}_{2} \mathrm{O}_{4}$ NPs was prepared using facile hydrothermal method. The asprepared $\mathrm{ZnFe}_{2} \mathrm{O}_{4}$ NPs capably employed for the detection of anti-inflammatory drug Nimesulide (NS) with the surface modification on the glassy carbon electrode (GCE). The physicochemical properties of as-prepared $\mathrm{ZnFe}_{2} \mathrm{O}_{4}$ NPs were characterized by XRD, FTIR, FESEM, HR-TEM, and XPS analysis. The electrocatalytic efficiency was investigated through EIS, CV, and DPV electroanalytical techniques. The obtained electroanalysis result demonstrated excellent electrocatalytic activity towards the detection of NS. The constructed $\mathrm{ZnFe}_{2} \mathrm{O}_{4}$ NPs modified electrode achieved a good linear ranging from 0.001 to 166 $\mu \mathrm{M}$ with a detection limit of $0.006 \mu \mathrm{M}$. The calculated analytical sensitivity of the sensor was $0.625 \mu \mathrm{A}$ $\mu \mathrm{M}^{-1} \mathrm{~cm}^{-2}$. Moreover, the modified electrode delivers good storage stability, reproducibility and repeatability. Evidently, the proposed sensor manifests the determination of NS in human urine samples and nimesulide tablets for practical applications.

Keywords: $\mathrm{ZnFe}_{2} \mathrm{O}_{4}$ nanoparticles, Nimesulide, human urine sample, pharmaceutical drug. 


\section{FULL TEXT}

(C) 2021 The Authors. Published by ESG (www.electrochemsci.org). This article is an open access article distributed under the terms and conditions of the Creative Commons Attribution license (http://creativecommons.org/licenses/by/4.0/). 